\title{
Incidence, etiology and predictors of adverse outcomes in 43,315 patients presenting to the Emergency Department with syncope: An international meta-analysis
}

\author{
Fabrizio D'Ascenzo a, i,*, Giuseppe Biondi-Zoccai b,i, Matthew J. Reed ${ }^{\text {d }}$, Gelareh Z. Gabayan ${ }^{\text {c }}$, Masaru Suzuki ${ }^{\text {e }}$, \\ Giorgio Costantino f, Raffaello Furlan ${ }^{\text {f }}$, Andrea Del Rosso ${ }^{\text {g, }}$ Francois P. Sarasin ${ }^{\text {h }}$, Benjamin C. Sun ${ }^{\text {c }}$, \\ Maria Grazia Modena ${ }^{\mathrm{b}}$, Fiorenzo Gaita ${ }^{\mathrm{a}}$
}

a University of Turin, Division of Cardiology, Italy

${ }^{\mathrm{b}}$ University of Modena and Reggio Emilia, Modena, Division of Cardiology, Italy

c Department of Medicine, Greater Los Angeles Veterans Affairs Healthcare System, USA

d Department of Emergency Medicine, Edinburgh, United Kingdom

e Department of Emergency Medicine, School of Medicine, Keio University, Tokyo, Japan

f Syncope Unit, Internal Medicine II, "L. Sacco" Hospital, University of Milan, Milan, Italy

g Department of Cardiology, Azienda USL 11 Empoli, Italy

${ }^{\text {h }}$ Division of Emergency Medicine, Hopital Cantonal, University of Geneva Medical School, Geneva, Switzerland

${ }^{\mathrm{i}}$ Meta-analysis and Evidence based medicine Training in Cardiology (METCARDIO), Italy

\section{A R T I C L E I N F O}

\section{Article history:}

Received 29 July 2011

Received in revised form 10 October 2011

Accepted 27 November 2011

Available online 20 December 2011

\section{Keywords:}

Syncope

Meta-analysis

Prognosis

Prognosis

Multivariate predictors

Emergency Department

\begin{abstract}
A B S T R A C T
Background: Syncope remains challenging for Emergency Department (ED) physicians due to difficulties in assessing the risk of future adverse outcomes. The aim of this meta-analysis is to establish the incidence and etiology of adverse outcomes as well as the predictors, in patients presenting with syncope to the ED. Methods: A systematic electronic literature review was performed looking for eligible studies published between 1990 and 2010. Studies reporting multivariate predictors of adverse outcomes in patients presenting with syncope to the ED were included and pooled, when appropriate, using a random-effect method. Adverse events were defined as 'incidence of death, or of hospitalization and interventional procedures because of arrhythmias, ischemic heart disease or valvular heart disease'.

Results: 11 studies were included. Pooled analysis showed 42\% (CI 95\%; 32-52) of patients were admitted to hospital. Risk of death was 4.4\% (CI 95\%; 3.1-5.1) and 1.1\% (CI 95\%; 0.7-1.5) had a cardiovascular etiology. One third of patients were discharged without a diagnosis, while the most frequent diagnosis was 'situational, orthostatic or vasavagal syncope' in 29\% (CI 95\%; 12-47). 10.4\% (CI 95\%; 7.8-16) was diagnosed with heart disease, the most frequent type being bradyarrhythmia, 4.8\% (CI 95\%; 2.2-6.4) and tachyarrhythmia 2.6\% (CI 95\%; 1.1-3.1). Palpitations preceding syncope, exertional syncope, a history consistent of heart failure or ischemic heart disease, and evidence of bleeding were the most powerful predictors of an adverse outcome.

Conclusion: Syncope carries a high risk of death, mainly related to cardiovascular disease. This large study which has established the most powerful predictors of adverse outcomes, may enable care and resources to be better focused at high risk patients.
\end{abstract}

(c) 2011 Elsevier Ireland Ltd. All rights reserved.

\section{Introduction}

Syncope is a common clinical presentation accounting for up to $3 \%$ of all Emergency Department (ED) visits and 6\% of hospital admissions [1]. Accurate diagnosis and assessment of prognosis [2] are required by ED physicians, as syncope may be due to a wide range of possible etiologies ranging from benign conditions to life-threatening diseases

\footnotetext{
* Corresponding author at: Dr. Fabrizio D'Ascenzo, Division of Cardiology, University of Turin, S. Giovanni Battista “Molinette" Hospital, Corso Bramante 88-90, 10126 Turin, Italy.

E-mail address: fabrizio.dascenzo@gmail.com (F. D'Ascenzo).
}

$[3,4]$. Focused inpatient investigation concentrating on high risk patients may save some of the 2 billion dollars spent every year in the United States of America on the hospitalization of patients with syncope $[5,6]$.

Several clinical decision rules (CDRs) and risk stratification scores have been derived to help physicians with diagnosis and risk assessment. These have performed less well when validated and applied to everyday clinical practice [7], possibly due to relatively small numbers of patients in each.

To our knowledge, no meta-analyses have been performed looking at either the short or long term diagnosis and prognosis of syncope and its most powerful predictors. The aim of this study is therefore to establish the incidence and etiology of adverse outcomes as well 
as the predictors, in patients presenting with syncope to the ED in order to offer physicians a more robust future assessment of risk.

\section{Methods}

The present research was conducted following current guidelines, including the recent Preferred Reporting Items for Systematic reviews and Meta-Analyses (PRISMA) amendment to the Quality of Reporting of Meta-analyses (QUOROM) statement, and recommendations from The Cochrane Collaboration and Meta-analysis Of Observational Studies in Epidemiology (MOOSE) [8-11].

\subsection{Search strategy and study selection}

Possible articles for inclusion were found using established search methods [12] looking for the terms "syncope", "multivariate predictors" and "adverse outcomes". The corresponding authors of possible studies were then directly contacted via email asking for further data and knowledge of further studies [13].

Two independent reviewers (GB-Z, FDA) initially screened all possible articles for inclusion at the title and/or abstract level, with disagreement resolved by consensus. If thought potentially eligible, the complete article was then reviewed according to the following strict selection criteria. Studies had to be both (i) investigating patients presenting to the ED with syncope AND (ii) reporting predictors of adverse outcomes after syncope using multivariate analysis methodology. Exclusion criteria were any of: (i) non-human study, (ii) duplicate reporting (in which case the manuscript reporting the largest sample of patients was selected) or (iii) differentiated syncope patients (i.e. studies recruiting patients with an already defined diagnosis of syncope e.g. cardiovascular cause only).

\subsection{Data extraction}

Two unblinded independent reviewers (GB-Z, FDA) abstracted the following data on pre-specified data collection forms: authors, journal, year of publication, location of the study group, baseline features, admission and death rates, inclusion and exclusion criteria, final identified cause of syncope (if any), multivariate predictors of adverse outcomes (point summary estimate of risk, with $95 \%$ confidence interval). Pre-defined end-points were incidence of in-hospital admission, incidence of adverse outcomes (defined as incidence of death, or of hospitalization and interventional procedures because of arrhythmias, ischemic heart disease or valvular heart disease') and final identified cause of syncope (if any).

\subsection{Internal validity and quality appraisal}

Unblinded independent reviewers (GB-Z, FDA) evaluated the quality of the selected studies on pre-specified data collection forms using modified MOOSE criteria to take into account the specific features of included studies [10]. The independent reviewers separately appraised study design, setting, data source, and statistical methods for multivariable analysis, as well as risk of analytical, selection, adjudication, detection, and attrition bias (expressed as low, moderate, or high risk of bias). Where present, incomplete reporting leading to inability to ascertain the underlying risk of bias was also recorded. All studies then received an overall score based as follows: Zero points were awarded for a retrospective design or single center study; One point for prospective design and/or multicenter setting; Two points were awarded for low risk of bias, one point for moderate risk of bias, and zero points for high risk or unclear risk of bias. If the total of these scores was 10 an overall 'very high' credibility rating was awarded, if the total was between 7 and 9 a 'high' credibility rating was awarded, if the total was between 4 and 6 a 'moderate' credibility rating was awarded, if the total was between 1 and 3, a 'low' credibility rating was awarded and for a total score of 0 , a 'very low' credibility rating was awarded (see Appendix Table B).
Table 1

Key features of included studies.

\begin{tabular}{ll}
\hline Studies & $\mathrm{N}=11$ \\
\hline $\begin{array}{l}\text { Study design } \\
\quad \text { Prospective cohort }\end{array}$ & $8(70 \%)$ \\
$\quad$ Retrospective cohort & $3(30 \%)$ \\
$\quad$ Data source & \\
$\quad$ Clinical database & $11(100 \%)$ \\
$\quad$ Years of publication & $2004-2009$ \\
$\quad$ Setting & \\
$\quad$ Single center & $5(45 \%)$ \\
$\quad$ Multicenter & $6(55 \%)$ \\
Location & $5(45 \%)$ \\
$\quad$ North America & $5(45 \%)$ \\
$\quad$ Europe & $1(10 \%)$ \\
$\quad$ Asia & 43,315 \\
Total patients presenting with syncope to the & $670(487-913)$ \\
$\quad$ Emergency Department & \\
$\quad$ Median number of patients per study (1st-3rd quartile) & $1(1-16)$ \\
Follow-up in months (median; 1 st-3rd quartile) & \\
\hline
\end{tabular}

\subsection{Data analysis}

Continuous variables are reported as mean (standard deviation) or median (range). Categorical variables are expressed as $\mathrm{n} / \mathrm{N}$ (\%). Statistical pooling was performed according to a random-effect model with generic inverse-variance weighting, computing risk estimates with 95\% confidence intervals, using RevMan 5 (The Cochrane Collaboration, The Nordic Cochrane Centre, and Copenhagen, Denmark). Graphical inspection of funnel plots was used to assess for study bias. Standard hypothesis testing was set at the two-tailed 0.05 level.

\section{Results}

201 citations were initially screened of which 17 reports were fully evaluated for consideration in the study. Three reports were excluded as they were non-ED studies [14-16], two were excluded because they reported differentiated patients with a pre-defined diagnosis of syncope (in both cases syncope patients with a diagnosis of cardiovascular syncope) $[17,18]$, one was excluded because it did not report multivariate predictors [2], and one study was excluded because of duplicate reporting [19]. 11 studies were finally included in the meta-analysis [20-30] (Fig. 1).

The main features of the included studies are reported in Table 1. Most of the studies were prospective, multicenter, with a median of 670 patients and a follow up of 1 month. While syncope was variably defined, all included papers essentially defined syncope according to the European Society of Cardiology 2009 guidelines (Table 2) [32].

Appendix Table B details the methodological validity of the 11 included studies. Logistic regression was the most frequent multivariate approach, with most of the studies reporting an overall high credibility. The main limitations were in adjudication and attrition bias.

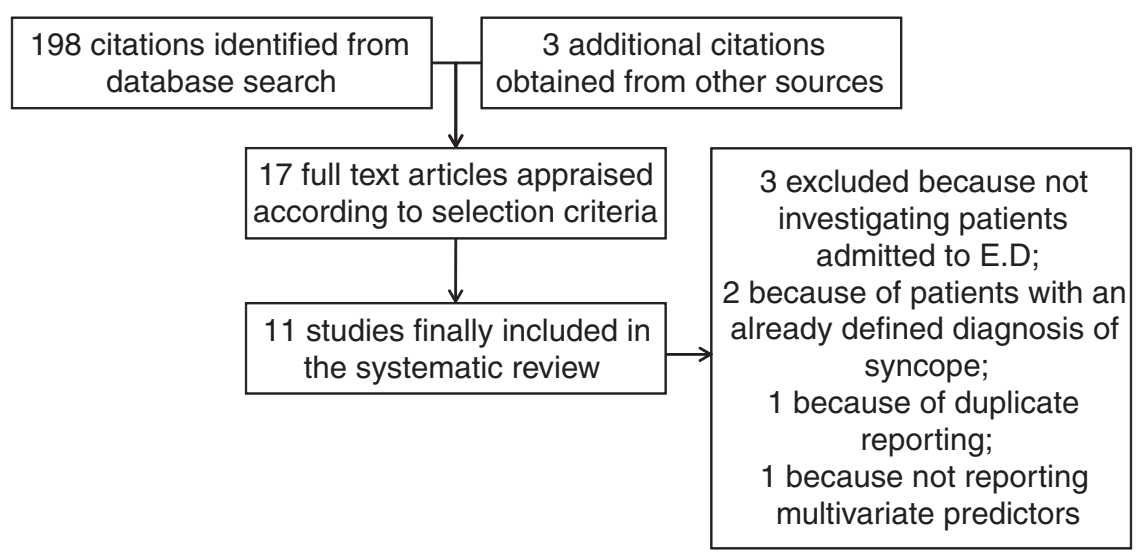

Fig. 1. Study flow diagram. 
Table 2

Inclusion and exclusion criteria of included studies.

\begin{tabular}{|c|c|c|}
\hline Author, journal, year & Inclusion criteria & Exclusion criteria \\
\hline OH, Arch Inter Med, 1999 & $\begin{array}{l}\text { Sudden transient loss of consciousness (LOC) } \\
\text { with an inability to maintain postural tone. }\end{array}$ & $\begin{array}{l}\text { Symptoms compatible with seizure disorder, vertigo, dizziness, coma, shock, } \\
\text { or other states of altered consciousness. }\end{array}$ \\
\hline Colivicchi, EHJ, 2003 & $\begin{array}{l}\text { Sudden and transient LOC and of postural tone } \\
\text { with spontaneous recovery. }\end{array}$ & $\begin{array}{l}\text { Pre-syncope, dizziness or vertigo, without a clear loss of consciousness or } \\
\text { already known seizure disorder and presenting a typical recurrence, with } \\
\text { prolonged post-ictal recovery phase. }\end{array}$ \\
\hline Sarasin, Acad Emer Med, 2003 & $\begin{array}{l}\text { Sudden transient LOC with an inability to maintain } \\
\text { postural tone, and with spontaneous recovery. }\end{array}$ & $\begin{array}{l}\text { Symptoms clearly compatible with seizure disorder, vertigo, dizziness, coma, } \\
\text { shock, or other states of altered consciousness. }\end{array}$ \\
\hline Suzuki, Ann Emerg Med, 2003 & $\begin{array}{l}\text { Sudden transient LOC with an inability to maintain } \\
\text { postural tone. }\end{array}$ & Seizure, vertigo, dizziness, coma, shock, or other altered states of consciousness. \\
\hline Quinn, Ann Inter Med, 2004 & Sudden transient LOC. & $\begin{array}{l}\text { Altered mental status, alcohol or illicit drug-related loss of consciousness, } \\
\text { a definite seizure, or transient loss of consciousness caused by head trauma. }\end{array}$ \\
\hline Sun, J Am Geriatr Soc, 2007 & Sudden transient LOC. & $\begin{array}{l}\text { Witnessed seizure, loss of consciousness after head trauma, ongoing } \\
\text { confusion (including baseline cognitive impairment or dementia), } \\
\text { intoxication, age younger than 18, inability to speak English or Spanish, } \\
\text { do-not-resuscitate (DNR) or do-not-intubate (DNI) status, and lack of } \\
\text { follow-up contact information. }\end{array}$ \\
\hline Costantino, JACC, 2008 & Sudden transient LOC. & $\begin{array}{l}\text { Presence of clinical conditions primarily confirmed in the ED that would have } \\
\text { required hospital admission independently of the syncope such as myocardial } \\
\text { infarction, acute pulmonary embolism, subarachnoid hemorrhage, stroke, } \\
\text { cardiac arrest, sustained bradycardia ( } 35 \text { beats/min), complete atrioventricular } \\
\text { block, sustained ventricular tachycardia; a referred head injury preceding the } \\
\text { loss of consciousness; a referred non-spontaneous return to consciousness; } \\
\text { non-syncopal syndromes such as light-headedness, vertigo, coma, shock, and } \\
\text { seizure; associated diseases with a prognosis less than } 6 \text { months; recent } \\
\text { alcohol or drug abuse; unwillingness to provide consent to participate in the } \\
\text { study; and unfeasible follow-up (foreigners, homeless). }\end{array}$ \\
\hline Del Rosso, BMJ, 2008 & Sudden transient LOC. & $\begin{array}{l}\text { Definite non-syncopal cause of loss of consciousness on the initial evaluation } \\
\text { (seizures, drop attacks, transient ischemic attacks, etc.), those aged, } 18 \text { years } \\
\text { and those referred } 24 \mathrm{~h} \text { after their episode. }\end{array}$ \\
\hline Sun, Ann Emerg Med, 2009 & $\begin{array}{l}\text { Sudden, transient loss of consciousness, and } \\
\text { near-syncope as a sensation of imminent loss } \\
\text { of consciousness. }\end{array}$ & $\begin{array}{l}\text { Generalized seizure, intoxication, no spontaneous return to baseline mental } \\
\text { status and patients who experienced loss of consciousness as a result of } \\
\text { head trauma. }\end{array}$ \\
\hline Gabayan, AJC, 2010 & Blackout, fainting (near), syncope, vasovagal attack. & $\begin{array}{l}\text { Carotid sinus syncope, heat syncope, neurocirculatory asthenia, orthostatic } \\
\text { hypotension, shock. }\end{array}$ \\
\hline Reed, JACC, 2010 & $\begin{array}{l}\text { Sudden transient LOC with an inability to maintain } \\
\text { postural tone. }\end{array}$ & $\begin{array}{l}\text { Persisting neurological deficit suggestive of stroke, previous recruitment into } \\
\text { the study, collapse related to alcohol consumption (raised alcometer reading } \\
\text { and no other cause for syncope), hypoglycemia, trauma, or seizure activity } \\
\text { with a less } 15 \text {-min witness reported postictal phase. }\end{array}$ \\
\hline
\end{tabular}

$45 \%$ of patients in the included studies were male, (41-60), reporting in $38 \%$ a history of previous syncope, and in 30\% a history of previous heart disease, most frequently arrhythmic (11\%) or ischemic heart disease (8\%) (Table 3 ).

Pooled analysis of outcomes and diagnosis of all included patients are reported in Tables 4 and 5 . At a median follow-up of 1 month, risk of death was $4.4 \%$, which was due to a cardiovascular etiology in $1.1 \%$. $42 \%$ of patients were admitted to hospital: $10.4 \%$ of patients were diagnosed with heart disease; the most frequent causes were bradyarrhythmic (4.8\%) and tachyarrhythmic disease (2.6\%). $29 \%$ of patients were discharged without a diagnosis and the most frequent diagnosis was situational, orthostatic or vasavagal syncope $(29 \%)$.

Table 3

Key patient characteristics.

\begin{tabular}{lc}
\hline Studies & $\mathrm{N}=11$ \\
\hline Age (years) & $63(60-64)$ \\
Male gender & $45 \%(41-60)$ \\
Diabetes & $12 \%(6-13)$ \\
Hypertension & $39 \%(35-43)$ \\
History of previous syncope & $38 \%(32-44)$ \\
History of heart disease & $30 \%(24-49)$ \\
History of arrhythmic heart disease & $11 \%(4-19)$ \\
History of ischemic heart disease & $8 \%(6-26)$ \\
History of heart failure & $8 \%(2-9)$ \\
History of valvular disease & $1 \%(0.2-4)$ \\
History of ischemic neurological disease. & $15 \%(8-21)$ \\
\hline
\end{tabular}

Reported as n (\%) or median (1st-3rd quartile).
The most powerful predictors of adverse outcome (Table 6 and Fig. 2) were palpitations preceding syncope, syncope during effort, a history consistent of heart failure or ischemic heart disease and clinical and laboratory evidence of bleeding.

\section{Discussion}

The most important findings of our meta-analysis are (a) patients presenting with syncope to the ED carry a low although significant risk of death, (b) one third of deaths are ascribable to cardiovascular diseases, (c) a large proportion of patients are still discharged without a clear diagnosis and (d) simple predictors could be useful to identify high risk patients.

Table 4

Pooled analysis of syncope etiology.

\begin{tabular}{lc}
\hline Diagnosis of cardiovascular disease & $10.4 \%(8-16)$ \\
- Rhythmic disease & $7.4 \%(4.5-10)$ \\
- Bradyarrhythmic disease & $2.6 \%(1.1-3.1)$ \\
- Tachiarrhythmic disease & $4.8 \%(2.2-6.4)$ \\
- Myocardial infarction & $1.7 \%(1-2.4)$ \\
- Aortic stenosis & $1.3 \%(0.7-2.1)$ \\
Diagnosis of stroke & $0.8 \%(0.5-0.9)$ \\
Diagnosis of situational, orthostatic or vasovagal syncope & $29 \%(9-49)$ \\
Diagnosis of pulmonary embolus & $0.6 \%(0.2-0.96)$ \\
Diagnosis of gastrointestinal bleeding/anemia & $2.4 \%(1.5-3.3)$ \\
Diagnosis of unexplained syncope & $29.6 \%(11-47)$ \\
\hline
\end{tabular}

Reported as\% (95\% CI). 
Table 5

Pooled analysis of patient's management and of adverse outcomes.

\begin{tabular}{lc}
\hline Studies & $\mathrm{N}=11$ \\
\hline Patients discharged to home & $58 \%(48-68)$ \\
Patients admitted to hospital & $42 \%(32-52)$ \\
Overall death & $4.4 \%(3.1-5.1)$ \\
Cardiovascular related death & $1.1 \%(0.7-1.5)$ \\
Non cardiovascular related death & $1.5 \%(0.7-2.4)$ \\
Unexplained death & $1.7 \%(0.2-3.3)$ \\
\hline Reported as\% (95\% CI). & \\
a Overall death was 4.36\% made up of cardiovascular death (1.1\%), non- \\
cardiovascular death (1.5\%) and unexplained death (1.73\%).
\end{tabular}

Syncope represents a common problem that practitioners often face in the ED or on a hospital ward. Emergency physicians take care of the initial management of patients, while further assessment of patients involves cardiologists and neurologists [32,33]. The diagnosis is often difficult due to many possible underlying causes [7], and because usually patients are totally asymptomatic during medical evaluation [20]. As seen from our data, all hospitalized patients still carry a significant risk of death, mainly related to cardiovascular causes, which persists, as previously showed, at long term [2].

In this study, syncope was thought to be due to situational, orthostatic or vasavagal causes [17] in up to one third of cases but still in one third of cases the etiology of syncope was not clear. Patients with situational syncope are not at risk of death or of adverse outcome and can be managed generally with lifestyle changes [7]. On the other hand unexplained syncope can have adverse outcome, and usually involves older and sicker patients [31].

Simple predictors of adverse outcomes could be very useful to identify high risk patients. In our meta-analysis, palpitations preceding syncope, syncope during effort, history of heart failure or ischemic heart disease and clinical and laboratory evidence or bleeding are the most powerful predictors of adverse outcome, while the most frequent to appear in the included studies are a history of heart disease and an abnormal electrocardiogram (ECG). Most of these factors are easy to assess, both through basic history and physical examination, and could improve diagnostic and therapeutic decision making (Table 6).

\section{Table 6}

Most common predictors of adverse outcome ${ }^{\mathrm{a}}$ after a syncopal episode identified in included studies.

\begin{tabular}{|c|c|}
\hline Studies & $\mathrm{N}=11(\%)$ \\
\hline Previous heart disease $\mathrm{b}^{\mathrm{b}}$ & $11(100)$ \\
\hline Abnormal Electrocardiogram $(E C G)^{c}$ & $11(100)$ \\
\hline Age (per 10 year increase) & $6(45)$ \\
\hline Abnormal values of blood pressure $(<90 \mathrm{~mm} \mathrm{Hg}$, or $>160 \mathrm{~mm} \mathrm{Hg}$ ) & $3(27)$ \\
\hline Male gender & $3(27)$ \\
\hline Clinical or laboratory evidence of bleeding ${ }^{d}$ & $2(18)$ \\
\hline
\end{tabular}

The following predictors were reported only in one study each:

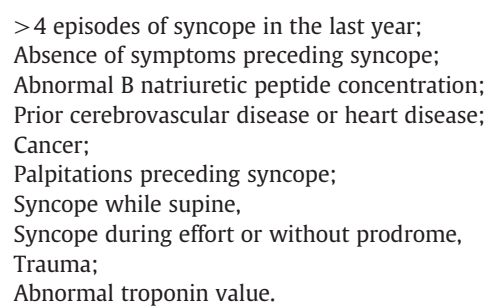

a Incidence of death, or of hospitalization and interventional procedures because of arrhythmias, ischemic heart disease or valvular heart disease.

b Previous heart failure or ischemic heart disease.

c Widely defined as Rhythm abnormalities, Atrioventricular or intraventricular conduction disorders and ST segment and T wave abnormalities consistent with or possibly related to myocardial ischemia.

d Diagnosed via complete/full blood count or rectal examination.

This work has many limitations. Firstly adverse outcomes were infrequent, thus leading to potential pitfalls in an accurate reporting [34]. Secondly, predictors were not pooled, mainly because this would have been fraught with a substantial selective reporting bias [35]. Because the present meta-analysis was based only on published studies, publication bias may be a problem, although small study bias was unapparent at funnel plot inspection (Fig. A, Appendix). Another weakness of our work was not performing an individual patient level meta-analysis. This could have provided more detailed information on incidence and predictors, but most likely would have required exclusion of several datasets thus limiting the study's external validity.

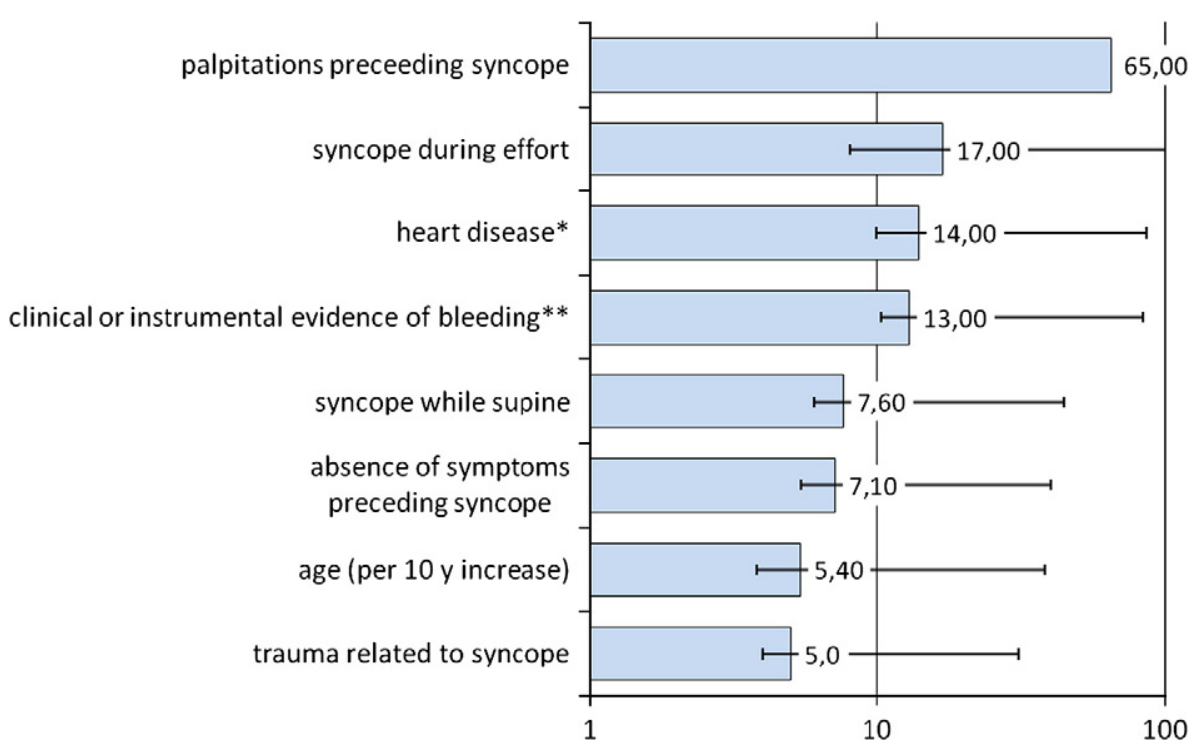

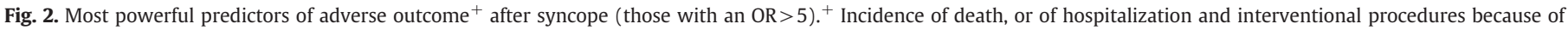

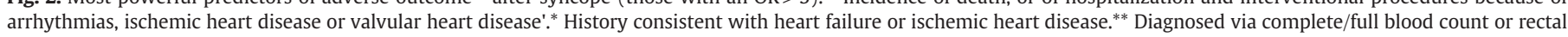
examination. 


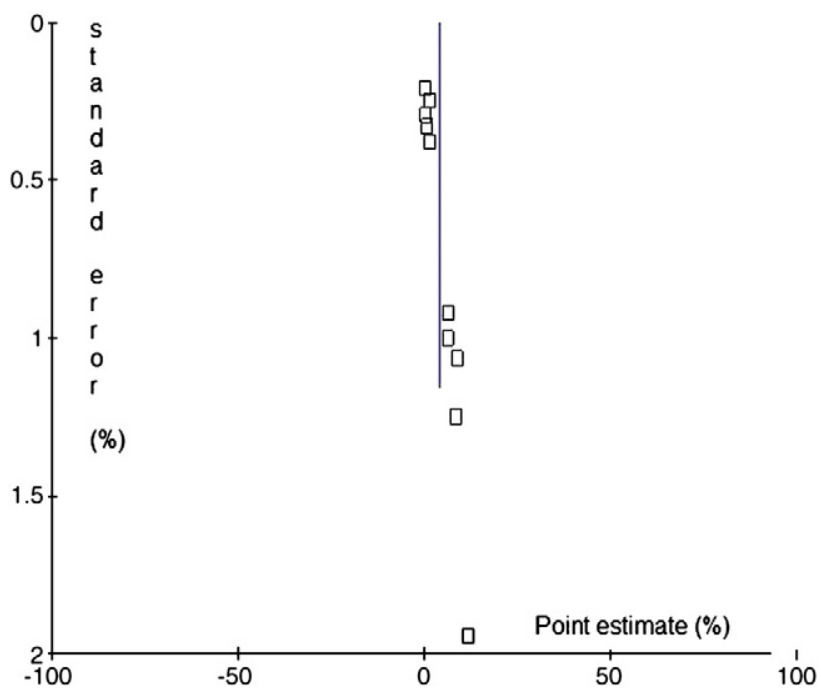

Fig. A. Funnel plot.

Because our study pooled smaller studies, it provides better data on more frequent syncope causes but does not provide any information on rarer causes such as short and long QT syndromes, or Brugada syndrome which may be expected to appear rarely in a study on 43 thousand patients [36,37].

Syncope carries a high risk of death, mainly related to cardiovascular disease. This large study which has established the most powerful predictors of adverse outcome may enable care and resources to be better focused at high risk patients. Future efforts should be focused on standardizing reporting criteria for ED syncope studies to allow better pooling of results from different centers.

\section{Acknowledgments}

Thanks to Alberto Milan for his outstanding support. The authors of this manuscript have certified that they comply with the Principles of Ethical Publishing in the International Journal of Cardiology.

\section{Appendix Table A. Assessment of bias}

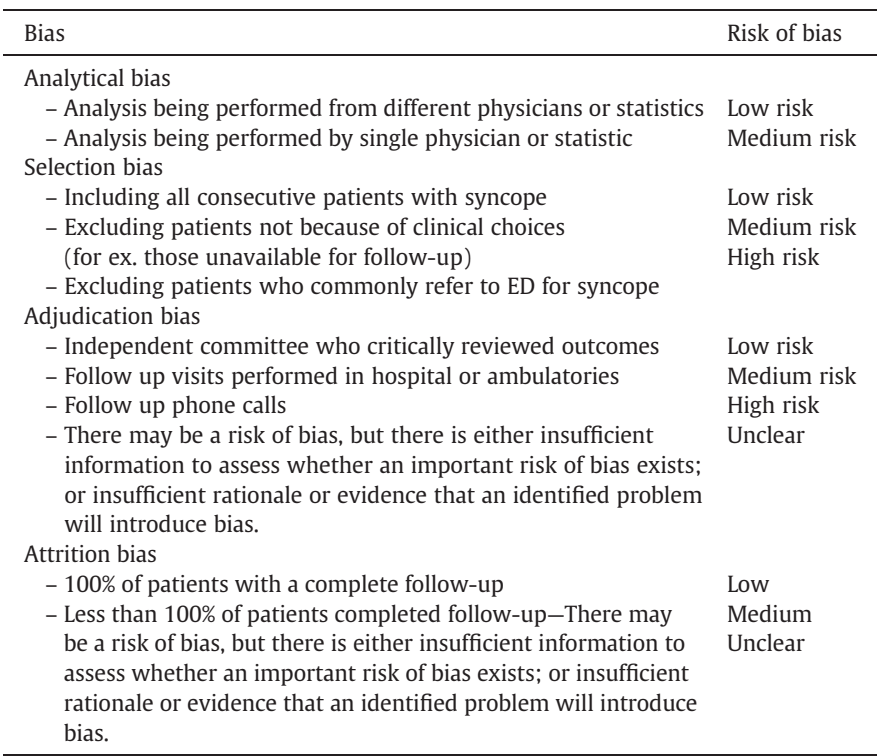

Appendix Table B. Internal validity of included studies

\begin{tabular}{lc}
\hline Studies & $\mathrm{N}=11$ \\
\hline $\begin{array}{l}\text { Multivariate analysis approach } \\
\text { Logistic regression }\end{array}$ & $8(73 \%)$ \\
$\quad$ Cox proportional hazard models & $2(18 \%)$ \\
$\quad$ Recursive partitioning & $1(9 \%)$ \\
Analytical bias & \\
$\quad$ Low risk & $6(55 \%)$ \\
$\quad$ Moderate risk & $5(45 \%)$ \\
Selection bias & \\
$\quad$ Low risk & $7(63 \%)$ \\
Moderate risk & $4(37 \%)$ \\
Adjudication bias & \\
Low risk & $7(63 \%)$ \\
$\quad$ Moderate risk & $4(37 \%)$ \\
Attrition bias & \\
Low risk & $5(45 \%)$ \\
Moderate risk & $6(55 \%)$ \\
Overall credibility & \\
Moderate & $3(27 \%)$ \\
High & $8(73 \%)$ \\
\hline
\end{tabular}

\section{References}

[1] Soteriades ES, Evans JC, Larson MG, et al. Incidence and prognosis of syncope. N Engl J Med 2002;347:878-85.

[2] Ungar A, Del Rosso A, Giada F, et al. Evaluation of Guidelines in Syncope Study 2 Group. Early and late outcome of treated patients referred for syncope to emergency department: the EGSYS 2 follow-up study. Eur Heart J 2010;31(16):2021-6.

[3] Kessler C, Tristano JM, De Lorenzo R. The emergency department approach to syncope: evidence-based guidelines and prediction rules. Emerg Med Clin North Am 2010;28(3):487-500.

[4] Kapoor WN. Syncope. N Engl J Med 2000;343:1856-62.

[5] Obama B. Modern health care for all Americans. N Engl J Med 2008;359(15): 1537-41.

[6] Sun BC, Emond JA, Camargo Jr CA. Direct medical costs of syncope-related hospitalizations in the United States. Am J Cardiol 2005;95:668.

[7] Serrano LA, Hess EP, Bellolio MF, et al. Accuracy and quality of clinical decision rules for syncope in the emergency department: a systematic review and meta-analysis. Ann Emerg Med 2010;56(4):362-73 e1.

[8] Moher D, Liberati A, Tetzlaff J, et al. PRISMA Group. Preferred reporting items for systematic reviews and meta-analyses: the PRISMA statement. BMJ 2009;339: b2535.

[9] Moher D, Cook DJ, Eastwood S, et al. Improving the quality of reports of meta-analyses of randomised controlled trials: the QUOROM statement. Quality of reporting of meta-analyses. Lancet 1999;354(9193):1896-900.

[10] Stroup DF, Berlin JA, Morton SC, et al. Meta-analysis of observational studies in epidemiology: a proposal for reporting. Meta-analysis Of Observational Studies in Epidemiology (MOOSE) group. JAMA 2000;283(15):2008-12.

[11] Higgins JPT, Green S, editors. Cochrane Handbook for Systematic Reviews of Interventions Version 5.0.2 [updated September 2009]. The Cochrane Collaboration; 2009. Available from www.cochrane-handbook.org.

[12] Wilczynski NL, Haynes RB, for the Hedges Team. Developing optimal search strategies for detecting clinically sound prognostic studies in MEDLINE: an analytic survey. BMC Med 2004;2:23.

[13] McManus RJ, Wilson S, Delaney BC, et al. Review of the usefulness of contacting other experts when conducting a literature search for systematic reviews. BMJ 1998;317:1562-3.

[14] Chen LY, Jahangir A, Decker WW, et al. Score indices for predicting electrophysiologic outcomes in patients with unexplained syncope. J Interv Card Electrophysiol 2005;14(2):99-105.

[15] Da Costa A, Gulian JL, Romeyer-Bouchard C, et al. Clinical predictors of cardiac events in patients with isolated syncope and negative electrophysiologic study. Int J Cardiol 2006;109(1):28-33.

[16] Fedorowski A, Burri P, Juul-Möller S, Melander O. A dedicated investigation unit improves management of syncopal attacks (Syncope Study of Unselected Population in Malmo-SYSTEMA I). Europace 2010;12(9):1322-8.

[17] Pfister R, Hagemeister J, Esser S, Hellmich M, Erdmann E, Schneider CA. NT-pro-BNP for diagnostic and prognostic evaluation in patients hospitalized for syncope. Int J Cardiol 2012 Mar 8;155(2):268-72.

[18] Haghjoo M, Faghfurian B, Taherpour M, et al. Predictors of syncope in patients with hypertrophic cardiomyopathy. Pacing Clin Electrophysiol 2009;32(5):642-7.

[19] Martin TP, Hanusa BH, Kapoor WN. Risk stratification of patients with syncope. Ann Emerg Med 1997;29(4):459-66.

[20] Colivicchi F, Ammirati F, Melina D, Guido V, Imperoli G, Santini M. OESIL (Osservatorio Epidemiologico sulla Sincope nel Lazio) Study Investigators. Development and prospective validation of a risk stratification system for patients with syncope in the emergency department: the OESIL risk score. Eur Heart J 2003;24(9):811-9. 
[21] Costantino G, Perego F, Dipaola F, et al. STePS Investigators. Short- and long-term prognosis of syncope, risk factors, and role of hospital admission: results from the STePS (Short-Term Prognosis of Syncope) study. J Am Coll Cardiol 2008;51(3): 276-83.

[22] Del Rosso A, Ungar A, Maggi R, et al. Clinical predictors of cardiac syncope at initial evaluation in patients referred urgently to a general hospital: the EGSYS score. Heart 2008;94(12):1620-6.

[23] Gabayan GZ, Derose SF, Asch SM, et al. Predictors of short-term (seven-day) cardiac outcomes after emergency department visit for syncope. Am J Cardiol 2010;105(1):82-6.

[24] Oh JH, Hanusa BH, Kapoor WN. Do symptoms predict cardiac arrhythmias and mortality in patients with syncope? Arch Intern Med 1999;159(4):375-80.

[25] Quinn JV, Stiell IG, McDermott DA, Sellers KL, Kohn MA, Wells GA. Derivation of the San Francisco Syncope Rule to predict patients with short-term serious outcomes. Ann Emerg Med 2004;43(2):224-32.

[26] Reed MJ, Newby DE, Coull AJ, Prescott RJ, Jacques KG, Gray AJ. The ROSE (risk stratification of syncope in the emergency department) study. J Am Coll Cardiol 2010;55(8):713-21.

[27] Sarasin FP, Hanusa BH, Perneger T, Louis-Simonet M, Rajeswaran A, Kapoor WN. A risk score to predict arrhythmias in patients with unexplained syncope. Acad Emerg Med 2003;10(12):1312-7.

[28] Sun BC, Derose SF, Liang LJ, et al. Predictors of 30-day serious events in older patients with syncope. Ann Emerg Med 2009;54(6):769-78 e1-5.

[29] Sun BC, Hoffman JR, Mangione CM, Mower WR. Older age predicts short-term, serious events after syncope. J Am Geriatr Soc 2007;55(6):907-12.

[30] Suzuki M, Hori S, Nakamura I, Soejima K, Aikawa N. Long-term survival of Japanese patients transported to an emergency department because of syncope. Ann Emerg Med 2004;44(3):215-21.
[31] Brignole M, Ungar A, Casagranda I, et al. Syncope Unit Project (SUP) investigators. Prospective multicentre systematic guideline-based management of patients referred to the Syncope Units of general hospitals. Europace 2010;12(1):109-18.

[32] Task Force for the Diagnosis and Management of Syncope; European Society of Cardiology (ESC); European Heart Rhythm Association (EHRA); Heart Failure Association (HFA); Heart Rhythm Society (HRS)Moya A, Sutton R, Ammirati F. Guidelines for the diagnosis and management of syncope (version 2009). Eur Heart J 2009;30(21):2631-71.

[33] American College of Emergency Physicians. Clinical policy: critical issues in the evaluation and management of patients presenting with syncope. Ann Emerg Med 2001;37:771-6.

[34] Agostoni P, Kedhi E, Verheye, et al. Dissimilar relevance given to diseases by medical literature, and the potential to create biases in the clinical decisionmaking process: the case of late stent thrombosis. Int J Cardiol 2007 Jan 8;114(2):E38-9.

[35] Ross JS, Mulvey GK, Stauffer B, et al. Statistical models and patient predictors of readmission for heart failure: a systematic review. Arch Intern Med 2008;168(13):1371-86.

[36] Delise P, Allocca G, Marras E, et al. Risk stratification in individuals with the Brugada type 1 ECG pattern without previous cardiac arrest: usefulness of a combined clinical and electrophysiologic approach. Eur Heart J 2011;32(2):169-76.

[37] Gaita F, Giustetto C, Bianchi F, et al. Short QT Syndrome: a familial cause of sudden death. Circulation 2003;108(8):965-70. 